\title{
Using high magnification to select sperm: a large prospective cohort study comparing ICSI and IMSI
}

Nino Guy Cassuto ${ }^{*}$, Dominique Bouret ${ }^{1}$, Ghada Hatem ${ }^{2}$, Lionel Larue ${ }^{3}$, Nathalie Lédée ${ }^{4}$, Lea Ruoso ${ }^{1}$, Flora Marzouk $^{1}$, André Hazout $^{5}$, Jan Tezarik $^{6}$, Jacques de Mouzon ${ }^{7}$, Kevin Zarca ${ }^{8}$, Adrian Shulman' and Anat Hershko Klement ${ }^{9}$

${ }^{1}$ ART Unit, Drouot Laboratory, 21 Rue Drouot 75009 Paris, France

${ }^{2}$ IVF Center Delafontaine-Drouot, Delafontaine Hospital, 93200 Saint-Denis, France

${ }^{3}$ IVF Center Diaconesses-Drouot, Diaconesses Saint Simon Hospital, 75012 Paris, France

${ }^{4}$ IVF Center Bluets-Drouot, Les Bluets Hospital, 75012 Paris, France

${ }^{5}$ ATL R\&D Laboratory, 4 Rue Louis Normand, 78320 La Verrière, France

${ }^{6}$ Clinica MARGen, 19 Rey Abu-Said, 18006 Granada, Spain

${ }^{7}$ Inserm U 149, 123 Boulevard de Port-Royal, 75014 Paris, France

${ }^{8}$ MEDISTICA, 48 Rue Lacordaire, 75015 Paris, France

IVF Unit, Meir Medical Center, Kfar Saba, Israel

\begin{abstract}
Purpose: To compare two methods for the observation and selection of spermatozoa before microinjection.

Methods: We analyzed 9012 treatment cycles - 3339 cycles of intracytoplasmic sperm injection (ICSI) (37.1\%) and 5673 cycles of intracytoplasmic injection of morphologically selected spermatozoa (IMSI) (62.9\%)—for fertilization, pregnancy, live birth, and miscarriage rates. The primary endpoints were clinical pregnancy rate and live birth. Secondary endpoints were fertilization, blastulation, and miscarriage rates.

Results: In the ICSI group, 530 cycles $(15.9 \%)$ ended with no embryos appropriate for transfer or freezing, versus 426 cycles $(7.5 \%)$ in the IMSI group $(P<0.01)$. After correction for age, body mass index, anti-Müllerian hormone level, and number of previous treatments, IMSI cycles were more likely to end in a pregnancy (odds ratio $[\mathrm{OR}] 1.17, P=0.009$ ). When the cohort was adjusted according to total motile sperm count, IMSI performed particularly well in cases with severe oligozoospermia: 70\% more pregnancies (OR 1.68, 95\% confidence interval [CI] 1.19-2.35) and twice as many live births (OR 2.05, 95\% CI 1.36-3.08) compared with ICSI. The miscarriage rate was also significantly lower using IMSI (13.5\%) than with ICSI $(23.2 \%)(P=0.03)$.
\end{abstract}

Conclusion: We recommend that IMSI be considered immediately in cases of severe male factor infertility, and as a second-line approach in cases of ICSI failure.

\section{Introduction}

Infertility is a common condition, affecting approximately $15 \%$ of the population. In $50 \%$ of cases a male factor is involved, making defective sperm function the largest single cause of human infertility [1]. Since the revolutionary intracytoplasmic sperm injection (ICSI) procedure was first introduced in 1992 [2], additional interventions have been sought to further improve the success rates of assisted reproductive technology (ART). Sperm quality is one of the main factors determining the fate of the embryo [3], and sperm epigenetic signature plays a large role in deciding embryonic development [4]. Injecting abnormal sperm DNA into the oocyte might end in failure of fertilization or zygote failure [5]. Even after fertilization, defective sperm might lead to early embryonic development disturbance, failure of blastocyst formation, miscarriages, and birth defects [6].

The ability to select sperm at high magnification $(\mathrm{HM})(\times 6100)$ led to the development of intracytoplasmic injection of morphologically selected spermatozoa (IMSI) [7]. However, the process was not well defined and was considered to be time-consuming. IMSI did not provide any significant improvement in clinical outcomes compared with ICSI in terms of implantation, clinical pregnancy, or live birth rates [8].
However, several recent studies have assessed the efficiency of IMSI and provided reassuring evidence for its use in specific indications $[9,10]$; patients with two or more previous failed ICSI attempts benefited the most in terms of increasing pregnancy rate and decreasing miscarriage rates $[11,12]$.

We present here the results from a large prospective cohort study comparing these two techniques in terms of pregnancy and live birth rates according to several confounding factors.

\section{Materials and methods}

Our study compared the results of IMSI and conventional ICSI in one ART unit (Drouot Laboratory, Paris, France). The study population comprised couples with male infertility.

${ }^{*}$ Correspondence to: Nino Guy Cassuto, ART Unit, Drouot Laboratory, 21 Rue Drouot, 75009 Paris, France, E-mail: guycassuto@labodrouot.com

Key words: sperm selection, IMSI, ICSI, male infertility

Received: January 29, 2020; Accepted: February 07, 2020; Published: February 13,2020 


\section{Sperm morphology assessment}

The same sperm preparation was used for both ICSI and IMSI. Spermatozoa were examined after preparation with a bilayer gradient of isolate (99264; Irvine Scientific Santa Ana, CA, USA). Sperm selection was performed at low magnification $(\times 400)$ for ICSI and at HM $(\times$ $6100)$ for IMSI. HM power was achieved using Nomarski polarization optics with a primary magnification of $\times 1500$ and subsequent zooming to $\times 6100$.

Spermatozoa morphology was assessed at HM according to our previously published scoring scale [13]. Briefly, the head shape, presence of vacuoles, and base normalcy were scored as follows: 2 points for a normal head, with no asymmetrical nuclear extrusion and/ or invagination of the nuclear membrane, 3 points for no vacuoles, and 1 point for a normal base making a total of 6 points for a top-quality spermatozoon (Score 6). The worst sperm score (Score 0 ) is associated with all three abnormalities. The attribution of a different number of points to each of the parameters was based on our preliminary observations of the relationship between the presence of each of them in the injected spermatozoa and the dynamics of early embryo development, including the ability to reach the expanded blastocyst stage on day 5 [13].

None of these features can be detected at the low magnification $(x$ 400) used in conventional ICSI.

\section{Sperm injection}

ICSI was performed as described elsewhere [2]. IMSI was performed after ICSI failure or when the proportion of Score 0 spermatozoa exceeded $40 \%$. This value was chosen following evaluation of the Score 0/Score 6 ratio (using 200 spermatozoa per patient) in a group of 500 men with normal sperm parameters, which varied from $15 \%$ to $40 \%$. We thus considered $40 \%$ Score 0 spermatozoa to be the threshold above which the IMSI procedure was necessary.

\section{Data collection}

The study protocol was approved by the local ethical committee of Bluets Hospital and conducted at the Assisted Reproduction Unit of the Drouot Laboratory (starting on January 26, 2010). After consultation with the Institutional Review Board, it was found that its approval was not mandatory because the study was of a non-interventional design. All the patients included signed a consent form informing them that their semen would be selected under HM. Patients were informed that all results would be communicated anonymously to the French health authorities (Bio Medical Agency, Saint-Denis, France).

Data collected included the age of the female partner, body mass index (BMI), rank of previous number of cycles with a failure, anti-Müllerian hormone (AMH) level, basal ovarian status on day 3, total gonadotropin dose used for ovarian stimulation, sperm characteristics on the retrieval day, number of collected oocytes, and treatment outcome. All ICSI and IMSI pregnancies and live births were achieved only with fresh ejaculated sperm and with fresh embryo transfer, excluding testicular and epididymis sperm or frozen sperm and embryos. The primary endpoints were pregnancy and live birth rates. Pregnancy was determined by a positive $\beta$-human chorionic gonadotropin blood test, followed by ultrasound visualization of a gestational sac with an embryonic pole and heartbeat.

Birth was defined as a delivery that occurred after 28 weeks of gestation. Miscarriage rate was a secondary endpoint, defined as unintentional termination of the pregnancy before 28 weeks. Total motile sperm count (TMSC) was calculated based on the pre-wash sperm provided on the day of retrieval.

\section{Statistical analysis}

Data analysis was performed using the SPSS 23.0 computer package (SPSS Inc., Chicago, IL, USA). Normally distributed data were analyzed with Student's $t$ test. $\chi^{2}$ analysis was used for comparisons of rates and proportions. Numeric variables are presented as mean \pm standard deviation and all $P$ values were tested as two-sided and considered significant at less than 0.05 . A linear model for fertilization and blastulation outcomes was pre-formed.

A multivariate logistic regression model for clinical pregnancy and live birth was developed using age, BMI, AMH, and number of previous treatments as variables.

Logistic regression models were also used to compute the odds ratios (OR) of pregnancy and live birth rates in ICSI versus IMSI cycles in a matrix categorized by age and TMSC. ORs are given with their $95 \%$ confidence intervals, as are mean differences in the linear model.

\section{Results}

The cohort included 9012 cycles: 3339 ICSI cycles (37.1\%) and 5673 IMSI cycles (62.9\%). Demographic data and cycle outcomes according to treatment modality are presented in Tables 1 and 2. The IMSI population was older and had higher BMIs and more previous failed treatments. Follicle-stimulating hormone (FSH) $(P=0.32), \mathrm{AMH}$ $(P=0.09)$, and smoking rates $(P=0.9)$ were similar in the two groups (Table 1).

The fertilization rate and blastulation rate were both significantly higher in the IMSI than the ICSI group $(P<0.01)$ (Table 2). No embryos appropriate for transfer or for freezing were obtained in $530(15.9 \%)$ ICSI cycles; however, this occurred in 426 (7.5\%) IMSI cycles $(P<0.01)$ (Table 2).

Crude, unadjusted pregnancy rate $(P=0.21)$ and live birth rate $(P=0.9)$ were equivalent in the two groups (Table 2$)$. The treatment modalities were tested for both pregnancy and live birth in a linear logistic regression corrected for age of female partner, BMI, AMH, and number of previous failed treatments (Table 3). Increased age of female partner, BMI, and additional treatments negatively affected the chance of clinical pregnancy and live birth (Table 3 ). To achieve pregnancy and live birth, the effect magnitude, although statistically significant, was rather low. Pregnancy chance was higher for IMSI (OR 1.17, $P=0.009$ ) (Table 3).

Table 1. Patient characteristics according to treatment modality

\begin{tabular}{|c|c|c|c|}
\hline \multirow{2}{*}{ Characteristic } & \multicolumn{2}{|c|}{$\begin{array}{c}\text { Treatment modality } \\
(\text { mean } \pm \text { SD, or } n(\%))\end{array}$} & \multirow{2}{*}{$\boldsymbol{P}$ value } \\
\cline { 2 - 3 } & $\begin{array}{c}\text { ICSI cycles } \\
n=3339\end{array}$ & $\begin{array}{c}\text { IMSI cycles } \\
n=5673\end{array}$ & \\
\hline $\begin{array}{c}\text { Female age } \\
\text { at treatment, } \\
\text { years }\end{array}$ & $34.80 \pm 4.75$ & $35.93 \pm 4.34$ & $<0.01$ \\
\hline FSH, mUI/mL & $4.99 \pm 6.42$ & $5.22 \pm 12.40$ & 0.32 \\
\hline AMH, ng/mL & $1.99 \pm 2.89$ & $2.10 \pm 2.84$ & 0.09 \\
\hline $\begin{array}{c}\text { Body mass } \\
\text { index }\end{array}$ & $24.86 \pm 4.78$ & $23.17 \pm 4.24$ & $<0.01$ \\
\hline $\begin{array}{c}\text { Number of } \\
\text { treatments }\end{array}$ & $1.6 \pm 0.97$ & $2.0 \pm 1.29$ & $<0.01$ \\
\hline Smokers & $1408(42.2)$ & $2395(42.2)$ & 0.9 \\
\hline
\end{tabular}


Table 2. Cycle performance by treatment modality

\begin{tabular}{|c|c|c|c|}
\hline \multirow{2}{*}{ Cycle performance } & \multicolumn{2}{|c|}{$\begin{array}{l}\text { Treatment modality } \\
(\text { mean } \pm \mathrm{SD} \text {, or } n(\%))\end{array}$} & \multirow{2}{*}{$P$ value } \\
\hline & $\begin{array}{c}\text { ICSI cycles } \\
n=3339\end{array}$ & $\begin{array}{c}\text { IMSI cycles } \\
n=5673\end{array}$ & \\
\hline Total number of embryos & $5.42 \pm 3.76$ & $5.50 \pm 3.74$ & 0.4 \\
\hline Fertilization & $71.12 \pm 32.27$ & $78.55 \pm 23.86$ & $<0.01$ \\
\hline Embryos frozen & $0.79 \pm 1.566$ & $0.76 \pm 1.578$ & 0.5 \\
\hline Blastulation & $27.51 \pm 36.89$ & $31.62 \pm 37.88$ & $<0.01$ \\
\hline Cycles ending in fresh transfer & $2665(79.8)$ & $5010(88.3)$ & $<0.01$ \\
\hline $\begin{array}{l}\text { Cycles ending in no embryos suitable for } \\
\text { fresh transfer or freezing }\end{array}$ & $530(15.9)$ & $426(7.5)$ & $<0.01$ \\
\hline $\begin{array}{l}\text { Unadjusted clinical pregnancy rate/cycle } \\
\text { initiated }\end{array}$ & $905(27.1)$ & $1608(28.3)$ & 0.21 \\
\hline Unadjusted live birth rate/cycle initiated & $488(14.6)$ & $832(14.7)$ & 0.9 \\
\hline
\end{tabular}

Table 3. Logistic regression models for clinical pregnancy and live birth

\begin{tabular}{|c|c|c|c|c|c|c|c|c|}
\hline \multirow{3}{*}{ Variable } & \multicolumn{4}{|c|}{ Clinical pregnancies } & \multicolumn{4}{|c|}{ Live births } \\
\hline & \multirow{2}{*}{$P$ value } & \multirow{2}{*}{ OR } & \multicolumn{2}{|c|}{$95 \%$ confidence interval for OR } & \multirow{2}{*}{$P$ value } & \multirow{2}{*}{ OR } & \multicolumn{2}{|c|}{$95 \%$ confidence interval for $\mathrm{OR}$} \\
\hline & & & Lower & Upper & & & Lower & Upper \\
\hline Age & 0.001 & 0.92 & 0.91 & 0.93 & 0.001 & 0.91 & 0.90 & 0.93 \\
\hline BMI & 0.001 & 0.97 & 0.96 & 0.99 & 0.001 & 0.96 & 0.94 & 0.97 \\
\hline $\mathrm{AMH}(\mathrm{ng} / \mathrm{mL})$ & 0.001 & 1.03 & 1.01 & 1.04 & 0.002 & 1.03 & 1.01 & 1.05 \\
\hline $\begin{array}{c}\text { Treatment } \\
\text { number }\end{array}$ & 0.03 & 0.94 & 0.90 & 0.99 & 0.01 & 0.92 & 0.86 & 0.98 \\
\hline IMSI vs ICSI & 0.009 & 1.17 & 1.04 & 1.32 & 0.25 & 1.09 & 0.94 & 1.26 \\
\hline
\end{tabular}

Table 4. Odds ratio matrix for (a) clinical pregnancy and (b) live births: IMSI vs ICSI according to treatment and TMSC (in millions) on the day of retrieval (corrected for age, AMH, BMI, and cycle number)

\section{4a. Clinical pregnancy}

\begin{tabular}{|c|c|c|c|c|c|c|c|c|}
\hline \multirow[b]{2}{*}{ Variable } & \multicolumn{2}{|c|}{$\mathrm{TMSC} \leq 1$} & \multicolumn{2}{|c|}{ TMSC $>1$ to 3} & \multicolumn{2}{|c|}{ TMSC $>3$ to 10} & \multicolumn{2}{|c|}{$\mathrm{TMSC}>10$} \\
\hline & $\begin{array}{c}\text { OR } \\
(95 \% \mathrm{CI})\end{array}$ & $P$ value & $\begin{array}{c}\text { OR } \\
(95 \% \mathrm{CI})\end{array}$ & $P$ value & $\begin{array}{c}\text { OR } \\
(95 \% \mathrm{CI})\end{array}$ & $P$ value & $\begin{array}{c}\text { OR } \\
(95 \% \mathrm{CI})\end{array}$ & $P$ value \\
\hline $\begin{array}{l}\text { Female partner age } \\
<30 \text { years }\end{array}$ & $0.97(0.55-1.71)$ & 0.9 & $0.66(0.28-1.56)$ & 0.3 & $1.18(0.65-2.18)$ & 0.6 & $0.86(0.59-1.27)$ & 0.5 \\
\hline $\begin{array}{l}\text { Female partner age } \\
30 \text { to } 40 \text { years }\end{array}$ & $1.68(1.19-2.35)$ & 0.03 & $1.20(0.69-2.07)$ & 0.5 & $1.37(0.95-1.95)$ & 0.08 & $1.13(0.92-1.37)$ & 0.2 \\
\hline $\begin{array}{l}\text { Female partner age } \\
>40 \text { years }\end{array}$ & $2.2(0.56-9.14)$ & 0.2 & $1.8(0.18-18.05)$ & 0.6 & $0.68(0.22-2.12)$ & 0.5 & $1.15(0.68-1.95)$ & 0.6 \\
\hline
\end{tabular}

4b. Live births

\begin{tabular}{|c|c|c|c|c|c|c|c|c|}
\hline \multirow[b]{2}{*}{ Variable } & \multicolumn{2}{|c|}{ TMSC $\leq 1$} & \multicolumn{2}{|c|}{ TMSC $>1$ to 3} & \multicolumn{2}{|c|}{ TMSC $>3$ to 10} & \multicolumn{2}{|c|}{ TMSC $>10$} \\
\hline & $\begin{array}{c}\text { OR } \\
(95 \% \mathrm{CI})\end{array}$ & $P$ value & $\begin{array}{c}\text { OR } \\
(95 \% \mathrm{CI})\end{array}$ & $P$ value & $\begin{array}{c}\text { OR } \\
(95 \% \mathrm{CI})\end{array}$ & $P$ value & $\begin{array}{c}\text { OR } \\
(95 \% \mathrm{CI})\end{array}$ & $P$ value \\
\hline $\begin{array}{c}\text { Female partner age } \\
<30 \text { years }\end{array}$ & $1.44(0.76-2.73)$ & 0.2 & $\begin{array}{c}1.15 \\
(0.43-3.06)\end{array}$ & 0.7 & $\begin{array}{c}0.88 \\
(0.42-1.81)\end{array}$ & 0.7 & $\begin{array}{c}1.1 \\
(0.69-1.74)\end{array}$ & 0.6 \\
\hline $\begin{array}{c}\text { Female partner age } \\
30 \text { to } 40 \text { years }\end{array}$ & $2.05(1.36-3.08)$ & 0.01 & $1.27(0.65-2.47)$ & 0.4 & $1.02(0.68-1.55)$ & 0.9 & $0.89(0.69-1.14)$ & 0.4 \\
\hline $\begin{array}{c}\text { Female partner age } \\
>40 \text { years }\end{array}$ & N/A & N/A & N/A & N/A & $0.9(0.14-5.7)$ & 0.9 & $0.56(0.26-1.22)$ & 0.2 \\
\hline
\end{tabular}

In order to better demonstrate the clinical advantage of IMSI and the impact of spermatozoa selection at HM, we constructed a matrix of the following TMSC categories: TMSC $\leq 1$ million, TMSC $>1$ to 3 million, TMSC $>3$ to 10 million, and TMSC $>10$ million. These categories were then stratified according to female partner's age (Table $4 \mathrm{a}, \mathrm{b})$. All results were adjusted for the age of the female partner, $\mathrm{AMH}$, BMI, and number of previous treatments. When the female partner's age was 30 to 40 years, the matrix showed better results with IMSI in severe oligozoospermia (TMSC $\leq 1$ ): the chance of pregnancy was $70 \%$ higher $(P=0.03)($ OR $1.68,95 \%$ CI 1.19-2.35) (Table 4a) and the chance of live birth doubled ( $P=0.01$ ) (OR 2.05, 95\% CI 1.36-3.08) (Table $4 \mathrm{~b}$ ). When the cohort was stratified according to TMSC values, a significantly lower miscarriage rate was found with TMSC $\leq 1$ million (23.2\% in ICSI vs $13.5 \%$ in IMSI; $P=0.03$ ).

\section{Discussion}

To the best of our knowledge, this is the largest comparison of IMSI versus routine ICSI in cases of poor sperm and ICSI failure. Despite their poor baseline characteristics, subjects in the IMSI population were more likely to have an embryo suitable for transfer or freezing. We showed that HM sperm selection provides higher fertilization and blastulation rates [14].

Moreover, in an adjusted model, the IMSI group obtains better pregnancy and live birth rates, although only the pregnancy outcome 
reached statistical significance: an IMSI cycle was 1.17 times more likely to result in a clinical pregnancy than an ICSI attempt. The population most likely to benefit from IMSI was that with the poorest sperm [15].

IMSI was twice as likely to result in a live birth for female partners of 30 to 40 years of age. The influence of maternal age is well known in ART: after the age of 40 the mitochondrial DNA genome is reduced by a quarter [16].

Routine use of IMSI is considered too time-consuming by many teams; this study has shown that the benefits make it worthwhile.

Randomized trials comparing ICSI and IMSI are scarce and results inconsistent, probably due to the different inclusion criteria used. Some studies have found no difference between the techniques in term of oocyte fertilization rates and early embryo development [17], and that IMSI in the first instance is not beneficial [8], although clinical trials support IMSI in populations with poor sperm quality [18] and it has been demonstrated to be an efficient solution in cases of repeated implantation failures after ICSI $[19,20]$. This study reinforces these findings and emphasizes the benefit of IMSI, not only from the embryological point of view but also in terms of live birth rate, for sperm that perform poorly.

We recently showed a significant correlation between DNA damage and sperm head morphology, as well as between morphological scoring and chromatin decondensation [21-23], although not necessarily with structural chromosomal anomalies [24]. These works provide a rationale for the use of IMSI. We have also shown improvements in the risk of major birth defects after fertilization with spermatozoa selected according to our scoring scale $[25,26]$.

Although all spermatozoa in a given semen specimen share the same DNA sequence, they do not necessarily have the same patterns of DNA methylation. As DNA methylation is associated with sperm morphology, HM selection allows spermatozoa with abnormal DNA methylation to be discarded [27], which might explain the reduction in major birth defects. In contrast to the DNA fragmentation assay, which does not enable sperm selection for fertilization procedures, HM-based morphology selection is performed as part of the ART process.

The results of previous papers addressing the relationship between maternal age and the use of HM sperm selection relied on small groups and are inconsistent: poor responders of ovarian stimulation did not appear to benefit [28], but the same author previously showed that women aged $>37$ years did benefit [29]. Our large population enabled us to perform a stratified, adjusted analysis that portrays the effect of the procedure after correcting for multiple confounders, including the age of the female partner. In our cohort, the most substantial influence on pregnancy and live birth rates was the basal sperm performance. In women younger than 30 years, there was a trend for a higher live birth rate with the poorly performing sperm, but this trend did not reach statistical significance. It seems that oocytes from younger patients could overcome severe sperm defects [30].

We have demonstrated advantages of this specific ART technique after correcting for universal confounders related to the outcome measures tested. Despite this analysis, our results are still subject to bias, because the patients were not randomly allocated to the two treatment groups. Rather, this study presents a summary of a clinical algorithm assigning treatment based on specific diagnostic criteria and results of previous treatments. In the setting of limited cycles of in vitro fertilization, it is extremely difficult to conduct an unbiased clinical trial. Therefore, we tried to overcome possible biases by constructing multiple models, although obviously we could not adjust for every parameter. Nonrandomized studies that have previously been conducted in cases of repeated ICSI failures have also shown improved clinical outcomes using IMSI [31].

\section{Conclusions}

Selecting spermatozoa using a strict HM sperm-scoring system results in a better outcome in certain populations with poor-quality sperm. We demonstrated previously that this selection was not related to chromosomal abnormalities but was correlated with chromatin condensation and sperm DNA hypermethylation. We suggest that IMSI should be considered as a first-line procedure for severe male factor infertility and as a second-line procedure in cases of ICSI failure or when a previous attempt has demonstrated a lack of blastulation. Further studies are required to confirm our results.

\section{Acknowledgement}

Editorial assistance was provided by Lisa Stewart, $\mathrm{PhD}$ of Newmed Publishing Services.

\section{References}

1. Mehta A, Nangia AK, Dupree JM, Smith JF (2016) Limitations and barriers in access to care formale factor infertility. Fertil Steril 105: 1128-1137. [Crossref]

2. Palermo G, Joris H, Devroey P, Van Steirteghem AC (1992) Pregnancies after intracytoplasmic injection of single spermatozoon into an oocyte. Lancet 340: 17-18. [Crossref]

3. Miller D, Brinkworth M, Iles D (2010) Paternal DNA packaging in spermatozoa: more than the sum of its parts? DNA, histones, protamines and epigenetics. Reproduction 139: $287-301$

4. Denomme MM, McCallie BR, Parks JC, Schoolcraft WB, Katz-Jaffe MG (2017) Alterations in the sperm histone-retained epigenome are associated with unexplained male factor infertility and poor blastocyst development in donor oocyte IVF cycles. Hum Reprod 32: 2443-2455. [Crossref]

5. Shaoqin G, Zhenghui Z, Xueqian Z, Yuan H (2014) Epigenetic modifications in human spermatozoon and its potential role in embryonic development. Yi Chuan 36: 439-446. [Crossref]

6. Schagdarsurengin U, Paradowska A, Steger K (2012) Analysing the sperm epigenome roles in early embryogenesis and assisted reproduction. Nat Rev Urol 9: 609-619.

7. Bartoov B, Berkovitz A, Eltes F (2001) Selection of spermatozoa with normal nuclei to improve the pregnancy rate with intracytoplasmic sperm injection. $N$ Engl J Med 345: 1067-1068. [Crossref]

8. Leandri RD, Gachet A, Pfeffer J, Celebi C, Rives N, et al. (2013) Is intracytoplasmic morphologically selected sperm injection (IMSI) beneficial in the first ART cycle? A multicentric randomized controlled trial. Andrology 1: 692-697. [Crossref]

9. Knez K, Zorn B, Tomazevic T, Vrtacnik-Bokal E, Virant-Klun I (2011) The IMS procedure improves poor embryo development in the same infertile couples with poor semen quality: a comparative prospective randomized study. Reprod Biol Endocrinol 9: 123. [Crossref]

10. Klement AH, Koren-Morag N, Itsykson P, Berkovitz A (2013) Intracytoplasmic morphologically selected sperm injection versus intracytoplasmic sperm injection: a step toward a clinical algorithm. Fertil Steril 99: 1290-1293. [Crossref]

11. Antinori M, Licata E, Dani G, Cerusico F, Versaci C, et al. (2008) Intracytoplasmic morphologically selected sperm injection: a prospective randomized trial. Reprod Biomed Online 16: 835-841. [Crossref]

12. Setti AS, Braga DP, Figueira RC, Iaconelli A, Jr., Borges E (2014) Intracytoplasmic morphologically selected sperm injection results in improved clinical outcomes in couples with previous ICSI failures or male factor infertility: a meta-analysis. Eur $J$ Obstet Gynecol Reprod Biol 183: 96-103. [Crossref]

13. Cassuto NG, Bouret D, Plouchart JM, Jellad S, Vanderzwalmen P, et al (2009) A new real-time morphology classification for human spermatozoa: a link for fertilization and improved embryo quality. Fertil Steril 92: 1616-1625. [Crossref]

14. Vanderzwalmen P, Hiemer A, Rubner P, Bach M, Neyer A, et al. (2008) Blastocyst development after sperm selection at high magnification is associated with size and number of nuclear vacuoles. Reprod Biomed Online 17: 617-627. [Crossref] 
15. Wilding M, Coppola G, Di Matteo L, Palagiano A, Fusco E, et al. (2011) Intracytoplasmic injection of morphologically selected spermatozoa (IMSI) improves outcome after assisted reproduction by deselecting physiologically poor quality spermatozoa. $J$ Assist Reprod Genet 28: 253-262. [Crossref]

16. Bentov Y, Yavorska T, Esfandiari N, Jurisicova A, Casper RF (2011) The contribution of mitochondrial function to reproductive aging. J Assist Reprod Genet 28: 773-783. [Crossref]

17. De Vos A, Van de Velde H, Bocken G, Eylenbosch G, Franceus N, et al. (2013) Does intracytoplasmic morphologically selected sperm injection improve embryo development? Arandomized sibling-oocyte study. Hum Reprod 28: 617-626.

18. Balaban B, Yakin K, Alatas C, Oktem O, Isiklar A, et al. (2011) Clinical outcome of intracytoplasmic injection of spermatozoa morphologically selected under high magnification: a prospective randomized study. Reprod Biomed Online 22: 472-476. [Crossref]

19. Boitrelle F, Guthauser B, Alter L, Bailly M, Bergere M, et al. (2014) High-magnification selection of spermatozoa prior to oocyte injection: confirmed and potential indications. ReprodBiomed Online 28: 6-13. [Crossref]

20. Shalom-Paz E, Anabusi S, Michaeli M, Karchovsky-Shoshan E, Rothfarb N, et al (2015) Can intra cytoplasmatic morphologically selected sperm injection (IMSI) technique improve outcome in patients with repeated IVF-ICSI failure? A comparative study. Gynecol Endocrinol 31: 247-251. [Crossref]

21. Perdrix A, Travers A, Chelli MH, Escalier D, Do Rego JL, et al. (2011) Assessment of acrosome and nuclear abnormalities in human spermatozoa with large vacuoles. Human Reprod 26: 47-58. [Crossref]

22. Boitrelle F, Ferfouri F, Petit JM, Segretain D, Tourain C, et al. (2011) Large human sperm vacuoles observed in motile spermatozoa under high magnification: nuclear thumbprints linked to failure of chromatin condensation. Human Reprod 26: 1650-1658.

23. Cassuto NG, Hazout A, Hammoud I, Balet R, Bouret D, et al. (2012) Correlation between DNA defect and sperm-head morphology. Reprod Biomed Online 24: 211-218.
24. Cassuto NG, Le Foll N, Chantot-Bastaraud S, Balet R, Bouret D, et al. (2011) Sperm fluorescence in situ hybridization study in nine men carrying a Robertsonian or a reciprocal translocation: relationship between segregation modes and highmagnification sperm morphology examination. Fertil Steril 96: 826-832. [Crossref]

25. Cassuto NG, Hazout A, Bouret D, Balet R, Larue L, et al. (2014) Low birth defects by deselecting abnormal spermatozoa before ICSI. Reprod Biomed Online 28: 47-53. [Crossref]

26. Hershko-Klement A, Sukenik-Halevy R, Biron Shental T, Miller N, Berkovitz A (2016) Intracytoplasmic morphologically selected sperm injection and congenital birth defects: a retrospective cohort study. Andrology 4: 887-893. [Crossref]

27. Cassuto NG, Montjean D, Siffroi JP, Bouret D, Marzouk F, et al. (2016) Different levels of DNA methylation detected in human sperms after morphological selection using highmagnification microscopy. Biomed Res Int 2016: 6372171. [Crossref]

28. Setti AS, Braga DP, Figueira RC, Iaconelli A, Jr., Borges E, Jr. (2015) Poor-responder patients do not benefit from intracytoplasmic morphologically selected sperm injection. $J$ Assist Reprod Genet 32: 445-450. [Crossref]

29. Setti AS, Figueira RC, Braga DP, Aoki T, Iaconelli A, Jr., et al. (2013) Intracytoplasmic morphologically selected sperm injection is beneficial in cases of advanced maternal age: aprospective randomized study. Eur J Obstet Gynecol Reprod Biol 171: 286-290. [Crossref]

30. Simon L, Murphy K, Shamsi MB, Liu L, Emery B, et al. (2014) Paternal influence of sperm DNA integrity on early embryonic development. Hum Reprod 29: 2402-2412. [Crossref]

31. Hazout A, Dumont Hassan M, Junca AM, Cohen Bacrie P, Tesarik J (2006) High magnification ICSI overcomes paternal effect resistant to conventional ICSI. Reprod Biomed Online 12: 19-25.

Copyright: (C2020 Cassuto NG. This is an open-access article distributed under the terms of the Creative Commons Attribution License, which permits unrestricted use, distribution, and reproduction in any medium, provided the original author and source are credited. 